\title{
Early eczema and the risk of childhood asthma: a prospective, population-based study
}

\author{
Marit Saunes ${ }^{1,2,4^{*}}$, Torbjørn Øien ${ }^{1}$, Christian K Dotterud ${ }^{1}$, Pål R Romundstad ${ }^{1}$, Ola Storrø ${ }^{1}$, Turid L Holmen ${ }^{3}$ \\ and Roar Johnsen ${ }^{1}$
}

\begin{abstract}
Background: Severe eczema in young children is associated with an increased risk of developing asthma and rhino-conjunctivitis. In the general population, however, most cases of eczema are mild to moderate. In an unselected cohort, we studied the risk of current asthma and the co-existence of allergy-related diseases at 6 years of age among children with and without eczema at 2 years of age.

Methods: Questionnaires assessing various environmental exposures and health variables were administered at 2 years of age. An identical health questionnaire was completed at 6 years of age. The clinical investigation of a random subsample ascertained eczema diagnoses, and missing data were handled by multiple imputation analyses.

Results: The estimate for the association between eczema at 2 years and current asthma at 6 years was OR=1.80 (95\% Cl 1.10-2.96). Four of ten children with eczema at 6 years had the onset of eczema after the age of 2 years, but the co-existence of different allergy-related diseases at 6 years was higher among those with the onset of eczema before 2 years of age.

Conclusions: Although most cases of eczema in the general population were mild to moderate, early eczema was associated with an increased risk of developing childhood asthma. These findings support the hypothesis of an atopic march in the general population.

Trial registration: The Prevention of Allergy among Children in Trondheim study has been identified as ISRCTN28090297 in the international Current Controlled Trials database
\end{abstract}

Keywords: Eczema, Asthma, Child, Preschool, Cohort, Questionnaires

\section{Background}

The atopic march is a term used to describe the relationship between allergy-related diseases, starting with food allergy and eczema in early childhood, and the subsequent development of asthma and rhino-conjunctivitis. An association between eczema and asthma in childhood has been documented in several studies, and severe eczema is associated with an increased tendency to produce immunoglobulin $\mathrm{E}$ (IgE) and developing asthma [1-7]. The nature of the relationship between eczema and asthma has, however, been debated. Although these diseases share some genetic and environmental risk

\footnotetext{
* Correspondence: marit.saunes@ntnu.no

${ }^{1}$ Department of Public Health and General Practice, Norwegian University of Science and Technology, Trondheim, Norway

${ }^{2}$ Department of Dermatology, St Olav Hospital, Trondheim University

Hospital, Trondheim, Norway

Full list of author information is available at the end of the article
}

factors, it has been argued that eczema and asthma are unrelated and that the progression of eczema to asthma is due to the co-manifestation of eczema and wheezing early in life $[3,6]$. On the other hand, plausible biological pathways have been described, with eczema as the first step in a progressive atopic march leading to asthma and/or rhino-conjunctivitis [8,9]. It has also been argued that the atopic march is restricted to males only [1]. A defective skin barrier due to mutations in the gene encoding profilaggrin/filaggrin (FLG) is associated with increased trans-epidermal water-loss, dry skin, itching and eczema [10]. Studies on FLG mutations have not, however, found any association with FLG mutations and asthma/rhino-conjunctivitis in children who did not have eczema.

These findings suggest different phenotypes for both asthma and eczema [11-13].

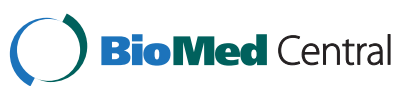

(c) 2012 Saunes et al.; licensee BioMed Central Ltd. This is an Open Access article distributed under the terms of the Creative Commons Attribution License (http://creativecommons.org/licenses/by/2.0), which permits unrestricted use, distribution, and reproduction in any medium, provided the original work is properly cited. 
Because previous studies have been based primarily on cross-sectional data, high-risk or hospitalised patients, population-based studies with prospective designs are warranted $[3,5,6,14,15]$. The aim of the present study was to prospectively investigate the association between a history of eczema at 2 years of age and current asthma at 6 years of age in a general population. We also aimed to determine the prevalence of allergy-related diseases at 6 years of age according to eczema status at 2 years of age.

\section{Methods}

The Prevention of Allergy among Children in Trondheim (PACT) study is a comprehensive, controlled, primary intervention study of allergy-related diseases in Trondheim, central Norway. The study is described in detail elsewhere [16]. Briefly, the control cohort included pregnant women and parents with their young children at ages 6 weeks, 1 year, 2 years and 6 years attending ordinary scheduled appointments with GPs, midwives or health-workers. The inclusion of 2-year-olds started on September $1^{\text {st }}$ of 2000 and closed on March $31^{\text {st }}$ of 2005 ; the inclusion of 6-year-olds started on September $1^{\text {st }}$ of 2000 and closed on December $31^{\text {st }}$ of 2008. In the present study, children from the PACT control cohort with cross-sectional data at 2 years were followed-up at the age of 6 years. In addition, we used information on sensitisation from a random subsample of children evaluated clinically at 2 years of age.

\section{Study variables}

Parents of children at age 2 (baseline) were given questionnaires concerning environmental exposures and the family history of different allergy-related diseases in the parents and siblings. A detailed questionnaire concerning the child's health, with an emphasis on allergyrelated diseases, was also administered. An identical health questionnaire was administered when the child was 6 years of age. The questions were adapted from the International Study of Asthma and Allergies in Childhood (ISAAC) study to fit both age groups.

Both questions "Has your child ever had eczema?" and "Has your child ever had an itchy rash which was coming and going for at least 6 months?" had to be answered positively to obtain the designation of "history of eczema" at 2 years of age. To identify children who had current eczema at 6 years of age, the two former questions were combined with "Has your child during the last 12 months used any kind of medication, ointment, cream, tablets or herbal medicines against eczema?" A history of asthma was denoted by a positive answer to the question "Has your child ever been diagnosed as having asthma by a doctor?" To obtain current asthma status, the former question was combined with a positive answer to "Has the child during the last 12 months used tablets, inhalation medications or other treatments for wheezing, tightness in the chest or asthma?"

The presence of wheezing was determined by a positive answer to both questions "Has your child ever had whistling in the chest?" and "Has your child ever had episodes of wheezing or tightness in the chest?"

Positive answers to the question "Has your child ever had hay fever, sneezing or itchy-watery eyes" defined a history of rhino-conjunctivitis.

A history of an allergy test was defined as an affirmative response to the question "Has your child ever been allergy tested by skin prick test or blood test?" A positive allergy test was present if the child's parent(s) reported a positive reaction to at least one allergen.

"Atopy in the family" was registered as present if the child's mother, father or any siblings had answered "yes" to one of several questions regarding asthma, eczema and allergic rhino-conjunctivitis.

The term "Homeowner" was used as a proxy for socioeconomic status and was based on the question "Do you/your family own your apartment/house".

\section{The random subsample}

From March 2001 to September 2002, a randomly sampled group of 720 pregnant women from the same control cohort described above were invited to attend a sub-study of PACT [17]. Their children were invited to a clinical examination at 2 years of age, including an assessment for eczema according to the United Kingdom Working Party (UKWP) diagnostic criteria. Disease severity was scored by the Scoring of Atopic Dermatitis (SCORAD) index and sensitisation was evaluated by standard prick test (SPT) and specific IgE (sIgE) measurements [14].

For SPT testing, the following standardised extracts from Soluprick ${ }^{\circledR}$ allergens (ALK Albello, Denmark) were used: mite (Dermatophagoides pteronyssinus), mould (Cladosporium herbarum), cat and dog dander, birch, timothy (grass) and mugwort pollens, hen's egg white, codfish, hazelnut and peanut. For cow's milk fresh skimmed milk was used. In addition, two positive histamine controls (Histamine $10 \mathrm{mg} / \mathrm{ml}$ ) and one diluentsnegative control $(\mathrm{NaCl})$ were applied on the volar surface of the child's forearms. A mean wheal diameter of at least $3 \mathrm{~mm}$ larger than the negative control was considered a positive test.

Sera from venous blood samples were analysed for sIgE using assays testing for the same allergens as the SPTs. Venous sampling was attempted only once. The sIgE analyses were carried out in the immunology laboratory at St Olavs University Hospital, Trondheim, using the Immulite ${ }^{\circledR} 2000$ Allergen-specific IgE system (Siemens Medical Solutions Diagnostics, Deerfield, IL, U.S.A.). A sIgE $\geq 0.35 \mathrm{kUL}^{-1}$ was considered positive. 
Sensitisation was defined as positive if the child either had a positive SPT or a positive sIgE.

\section{Statistics}

Baseline characteristics as well as allergy-related diseases are described as prevalences with $95 \%$ confidence intervals $(\mathrm{CI})$ for dichotomous variables.

Multivariable, logistic regression models were used to estimate the adjusted associations between a history of eczema at 2 years and current asthma at 6 years. Eczema and the age of eczema onset were used as explanatory variables. The age of eczema onset was divided in tertiles (0-3 months, 4-12 months, 13 months or older), and all other explanatory variables in the model were dichotomised. The possible confounding factors were identified by a priori knowledge, and in the final models, adjustments were made for sex, atopy in the family, wheezing, homeowner status and a smoking mother. Interaction on the multiplicative level was tested between eczema and sex and between eczema and wheezing using the likelihood ratio test. Children with a history of doctordiagnosed asthma at age 2 years were excluded from the follow-up analyses. In addition, follow-up analyses excluding both children with doctor-diagnosed asthma and children who had ever experienced wheezing at age 2 years were performed.

\section{Missing data analysis}

Due to the large amount of missing data, we used multiple imputations (MI) to assess the potential impact of missing data in the regression analyses. We assumed that data were missing at random given the results from the observed data, and we used chained equations (regression switching) with 50 sets of imputations to impute missing values as implemented in the STATA's ICE command. The following predictor variables reported at 2 years were included in the imputation model: eczema, age in tertiles, siblings, atopy in the family, a cat in the household, symptoms of wheezing/whistling in the chest, symptoms of hay fever, history of hospitalisation for any allergy-related diseases, homeowner status, smoking mother/father and sensitisation. In addition, the outcome variable, current asthma at 6 years, was included. Because reported sensitisation was not considered missing at random, sensitisation-data from the subsample, where all of the randomly selected participants included were tested regardless of the presence of disease symptoms, were used as predictors in the ICE command. A multiplicative interaction term between eczema and sensitisation was also included in the predictive ICE command and tested in the final models. For each outcome variable, a separate MI dataset was created, and resulting estimates were combined by the MIM command in STATA. To study the association between a history of eczema at 2 years and current asthma at 6 years, logistic regression analyses were performed on the MI dataset.

In addition to the multiple imputation approach, we also performed analyses based on individuals with complete data.

All data were analysed using STATA for Windows (version 11, College Station, Texas, USA).

\section{Ethics}

All parents signed a written consent form to participate in the PACT study. The Regional Committee for Medical Research Ethics and the Norwegian Data Inspectorate Board approved the study (Ref 120-2000) (Ref 2003/ 953-3 KBE/-).

The PACT study has been registered in Current Controlled Trials database (ISRCTN28090297).

\section{Results}

By March $31^{\text {st }}$ of 2005,4780 parents had completed the baseline questionnaires at their child's second year of age, and by April of 2009, 2192 (46\%) of these had also returned the health questionnaire when their children turned 6. Comparison of the baseline characteristics of the children with follow-up data at 6 years $(n=2192)$ and children with no follow-up data $(n=2588)$ are shown in Table 1. Apart from more "smoking mothers" and fewer "homeowners" among children with no follow-up data at 6 years, compared to children with follow-up data at 6 years, the two groups were comparable at baseline. In addition, the mothers of children with follow-up data were slightly older at delivery (mean age 29.8, $\pm 4.50 \mathrm{SD}$ vs. $28.9, \pm 4.79 \mathrm{SD}$ ). Among children with follow-up data at 6 years, the prevalence of eczema, asthma and wheezing at 2 years was $17.8 \%$ (95\% CI 16.2-19.5), 6.5\% (95\% CI 5.5-7.6) and $25.3 \%$ (95\% CI 23.5-27.2), respectively. The corresponding reported prevalences for children with no follow-up data showed only small and insignificant differences from these numbers (Table 1).

In Table 2, we compared the estimated prevalence of allergy-related diseases at 2 years of age among those with available data at baseline with the estimated prevalence using multiple imputations; no substantial differences were found. We also compared the estimated prevalence of allergy-related diseases among 6-year-olds with follow-up data to the estimated prevalence found using multiple imputations. The prevalence of asthma and rhino-conjunctivitis at 6 years of age tended to be higher using multiple imputation, but the differences were small (Table 3).

More than one-half (56\%) of the children with a history of eczema at 2 years did not report current eczema at age 6 years (Table 4). Approximately $42 \%$ of those with eczema at age 6 years had their first appearance of eczema after 2 years of age. 
Table 1 Baseline characteristics and prevalence of allergy-related diseases at 2 years of age

\begin{tabular}{|c|c|c|c|c|c|c|}
\hline & \multicolumn{3}{|c|}{ Children with follow-up data at 6 years $(\mathrm{N}=2192)^{\mathrm{a}}$} & \multicolumn{3}{|c|}{ Children without follow-up data at 6 years $(\mathrm{N}=2588)^{2}$} \\
\hline & $\mathrm{n} / \mathrm{N}$ & $\%$ & $95 \% \mathrm{Cl}$ & $\mathrm{n} / \mathrm{N}$ & $\%$ & $95 \% \mathrm{Cl}$ \\
\hline \multicolumn{7}{|l|}{ Characteristics } \\
\hline Male sex & 1080/2192 & 49.3 & $47.2-51.4$ & $1309 / 2586$ & 50.6 & 48.7-52.6 \\
\hline Sibling(s) & $1531 / 2160$ & 70.9 & $68.9-72.8$ & $1734 / 2554$ & 67.9 & $66.0-69.7$ \\
\hline Atopy in the family & $1474 / 2157$ & 68.3 & $66.3-70.3$ & $1733 / 2543$ & 68.1 & $66.3-70.0$ \\
\hline Breastfed $\geq 3$ months & 1862/1981 & 94.0 & 92.9-95.0 & $2191 / 2334$ & 93.9 & $92.8-94.8$ \\
\hline Ever antibiotics & $1008 / 2181$ & 46.2 & $44.1-48.3$ & $1188 / 2578$ & 46.1 & $44.1-48.0$ \\
\hline Dog at home & $163 / 2002$ & 8.1 & $7.0-9.4$ & $202 / 2364$ & 8.5 & $7.4-9.7$ \\
\hline Cat at home & $158 / 2002$ & 7.9 & $6.7-9.2$ & $239 / 2364$ & 10.1 & $8.9-11.4$ \\
\hline Homeowner & 1973/2159 & 91.4 & $90.1-92.5$ & $2145 / 2552$ & 84.1 & $82.6-85.5$ \\
\hline Smoking mother & $381 / 2124$ & 17.9 & 16.3-19.6 & $548 / 2503$ & 21.9 & 20.3-23.6 \\
\hline Smoking father & $346 / 1944$ & 17.8 & 16.1-19.6 & $461 / 2244$ & 20.5 & $18.9-22.3$ \\
\hline \multicolumn{7}{|l|}{$\underline{\text { Allergy related diseases }^{\mathrm{b}}}$} \\
\hline Eczema & $386 / 2169$ & 17.8 & $16.2-19.5$ & $402 / 2554$ & 15.7 & $14.3-17.2$ \\
\hline Doctor-diagnosed asthma & $143 / 2191$ & 6.5 & $5.5-7.6$ & $194 / 2587$ & 7.5 & $6.5-8.6$ \\
\hline Wheezing & $554 / 2189$ & 25.3 & $23.5-27.2$ & $701 / 2585$ & 27.1 & $25.4-28.9$ \\
\hline Rhino-conjunctivitis & $119 / 2182$ & 5.4 & $4.5-6.5$ & $160 / 2564$ & 6.2 & $5.3-7.2$ \\
\hline Allergy test performed & $462 / 2185$ & 21.1 & $19.4-22.9$ & $543 / 2569$ & 21.1 & $19.6-22.8$ \\
\hline Sensitisation (any) & $223 / 1973$ & 11.3 & $9.9-12.8$ & $272 / 2323$ & 11.7 & $10.4-13.1$ \\
\hline
\end{tabular}

${ }^{a}$ Numbers of missing data varies for different variables.

${ }^{b}$ Estimates of ever having the disease.

No substantial sex differences were found in the prevalence of eczema at 2 years. Overall, however, boys reported significantly more asthma than girls both at 2 years $(5.4 \%$ vs. $8.7 \%, \mathrm{p}<0.001)$ and at 6 years $(6.4 \%$ vs. $11.2 \%, \mathrm{p}<0.001)$.

Children with eczema at 2 years reported more asthma at both 2 and 6 years compared to those without eczema. The co-existence of eczema and rhinoconjunctivitis, eczema and asthma and asthma and rhino-conjunctivitis at 6 years of age among children with eczema at 2 years was $15 \%, 4.9 \%$ and $4.9 \%$, respectively. The corresponding numbers for those without eczema at 2 years were all less than 1\% (Figure 1).

Among children with follow-up data at 6 years (complete case analysis), the adjusted odds ratio between eczema at 2 years and current asthma at 6 years was 1.95 (95\% CI 1.07-3.54) (Table 5). When the age of onset for eczema was included in the model, an onset before four months of age (first tertile) was significantly associated with asthma at 6 years, adjusted $\mathrm{OR}=4.51$ (95\% CI 1.73-11.72) (Table 6). We found no basis for a multiplicative interaction between eczema and sex $(\mathrm{p}=0.83)$ or eczema and wheezing $(\mathrm{p}=0.13)$ for risk of asthma at 6 years.

The analysis using multiple imputations provided nearly the same associations as the complete case analysis. When information on sensitisation was included in the model, no substantial change in the association between eczema and asthma was found (Table 5). We repeated the analysis after removing all children who reported doctor diagnosed asthma (ever) at 2 years and children with wheezing (ever) at 2 years. The association

Table 2 Prevalence of allergy-related diseases and sensitisation in children at 2 years of age

\begin{tabular}{|c|c|c|c|c|c|}
\hline & \multicolumn{3}{|l|}{ Baseline } & \multicolumn{2}{|c|}{ Multiple imputation $(\mathrm{N}=4780)$} \\
\hline & $\mathrm{n}$ & $\%$ & $95 \% \mathrm{Cl}$ & $\%$ & $95 \% \mathrm{Cl}$ \\
\hline Eczema (ever) & $788 / 4723$ & 16.7 & $15.6-17.8$ & 17.4 & $16.3-18.5$ \\
\hline Asthma (ever) & $337 / 4778$ & 7.1 & $6.3-7.8$ & 7.1 & $6.3-7.8$ \\
\hline Wheezing (ever) & $1255 / 4774$ & 26.3 & $25.0-27.6$ & 27.7 & $26.4-29.0$ \\
\hline Sensitised ${ }^{a}$ & - & - & - - & 21.4 & $16.1-26.7$ \\
\hline
\end{tabular}

${ }^{a}$ Only children in the subsample were allergy tested. 
Table 3 Prevalence of allergy-related diseases in children at 6 years of age

\begin{tabular}{|c|c|c|c|c|c|}
\hline & Children $\mathrm{n}$ & ip dat & & Multiple & \\
\hline & $n$ & $\%$ & $95 \% \mathrm{Cl}$ & $\%$ & $95 \% \mathrm{Cl}$ \\
\hline Eczema (current) & $295 / 2171$ & 13.6 & $12.2-15.1$ & 14.0 & $12.5-15.5$ \\
\hline Asthma (current) & $121 / 2192$ & 5.5 & $4.6-6.6$ & 8.0 & $6.6-9.3$ \\
\hline Rhino-conjunctivitis (ever) & $255 / 2178$ & 11.7 & 10.4-13.1 & 14.7 & $12.9-16.5$ \\
\hline
\end{tabular}

between eczema at 2 years and asthma at 6 years was still significant with $\mathrm{OR}=2.06$ (95\% CI 1.09-3.90) (data not shown).

In the model with age of eczema onset categorised in tertiles, the association between age of eczema onset during the first tertile (before 4 months of age) and current asthma at 6 years did not indicate a clear trend or pattern for the age onset eczema and risk of asthma (Table 6). We found no evidence for a multiplicative interaction between eczema and sensitisation $(\mathrm{p}=0.70)$.

Boys had a slightly higher risk than girls of developing asthma, but the differences were not significant.

\section{The random subsample}

At age 2 years, 441 of 720 randomly selected children from the control cohort included since pregnancy were eligible for follow-up. Of these, 390 children (88\%) participated in a clinical examination. The prevalence of a history of eczema, doctor-diagnosed asthma and wheezing reported in questionnaires at 2 years was $21.0 \%$, $8.8 \%$ and $23.5 \%$, respectively. The prevalence of clinically investigated eczema according to the UKWP diagnostic criteria was $15.9 \%$.

An allergy test, either a SPT or a sIgE, was performed in $91 \%$ of the children. Of those with UKWP-Eczema, some $22.4 \%$ (95\% CI 12.5-35.3.4) had a positive test, while some $14.5 \%$ (95\% CI 10.7-19.0) of those without UKWP-Eczema tested positive $(\mathrm{p}=0.7)$.

\section{Discussion}

In this large, prospective study from the general population, we found a strong association between eczema at age 2 years and asthma at age 6 years. Asthma was reported more often among boys than girls, regardless of eczema status. Four out of ten children with eczema at age 6 had the onset of their eczema after 2 years of age, but the co-existence of allergy-related diseases reported at 6 years was higher among children with an onset of eczema before 2 years of age. More than one-half of the children with eczema during the first two years of life no longer had eczema when they turned 6 years.

This comprehensive study was conducted in the primary health care setting. However, as only close to half of the included children had follow-up data at 6 years, there is a possibility of selection bias [16]. The design of the PACT study is that of multiple, yearly, crosssectional cohorts of children consecutively included from the year 2000. During the inclusion period, we have observed a decline in the number of participants over time. However, a non-participant study carried out among 391 parents who consecutively attended maternal postnatal care revealed no substantial differences in age, education, familial allergy-related diseases and smoking behaviour when comparing participants and nonparticipants [16]. This trend is also supported by the baseline data and clinical characteristics among those children with follow-up data at 6 years compared with children with no follow-up data at 6 years. Apart from

Table 4 Prevalence of allergy-related diseases reported at 2 and 6 years by eczema-status and sex

\begin{tabular}{|c|c|c|c|c|c|c|c|c|c|c|c|c|c|c|c|}
\hline & \multicolumn{6}{|c|}{ Reported at 2 years } & \multicolumn{9}{|c|}{ Reported at 6 years } \\
\hline & \multicolumn{3}{|c|}{ Asthma } & \multicolumn{3}{|c|}{ Wheezing } & \multicolumn{3}{|c|}{ Eczema } & \multicolumn{3}{|c|}{ Asthma } & \multicolumn{3}{|c|}{ Rhino-conjunctivitis } \\
\hline & $n$ & $\%$ & $95 \% \mathrm{Cl}$ & $n$ & $\%$ & $95 \% \mathrm{Cl}$ & $\mathrm{n}$ & $\%$ & $95 \% \mathrm{Cl}$ & $\mathrm{n}$ & $\%$ & $95 \% \mathrm{Cl}$ & $\mathrm{n}$ & $\%$ & $95 \% \mathrm{Cl}$ \\
\hline \multicolumn{16}{|c|}{ Reported eczema 2 yrs } \\
\hline Total $(n=386)$ & 39 & 10.1 & $7.3-13.6$ & 134 & 34.7 & $30.0-39.7$ & 170 & 44.0 & $39.0-49.2$ & $41^{a}$ & 10.6 & 7.7-14.1 & 105 & 27.2 & $22.8-31.9$ \\
\hline Boys $(n=200)$ & 27 & 13.5 & $9.1-19.0$ & 76 & 38.0 & $31.2-45.1$ & 81 & 40.5 & $33.6-47.7$ & 24 & 12.0 & 7.8-17.3 & 57 & 28.5 & $22.4-35.3$ \\
\hline Girls $(n=186)$ & 12 & 6.4 & $3.4-11.0$ & 58 & 31.2 & $24.6-38.4$ & 89 & 47.8 & $40.5-55.3$ & 17 & 9.1 & $5.4-14.2$ & 48 & 25.8 & $19.7-32.7$ \\
\hline \multicolumn{16}{|c|}{ Reported no eczema 2 yrs } \\
\hline Total $(n=1783)$ & 102 & 5.7 & $4.7-6.9$ & 414 & 23.2 & $21.3-25.3$ & 123 & 6.9 & $5.8-8.2$ & $79^{b}$ & 4.4 & $3.5-5.5$ & 148 & 8.3 & $7.1-9.7$ \\
\hline Boys $(n=863)$ & 65 & 7.5 & $5.9-9.5$ & 222 & 25.7 & $22.8-28.8$ & 49 & 5.7 & $4.2-7.4$ & 53 & 6.1 & $4.6-8.0$ & 88 & 10.2 & $8.3-12.4$ \\
\hline Girls $(n=920)$ & 37 & 4.0 & $2.8-5.5$ & 192 & 20.9 & $18.3-23.6$ & 74 & 8.0 & $6.4-10.0$ & 26 & 2.8 & $1.9-4.1$ & 60 & 6.5 & $5.0-8.3$ \\
\hline
\end{tabular}

${ }^{a}$ In children with eczema at 2 years: 22/41 children reporting asthma at 6 years also reported asthma at 2 years.

${ }^{b}$ In children without eczema at 2 years: $42 / 79$ children reporting asthma at 6 years also reported asthma at 2 years. 

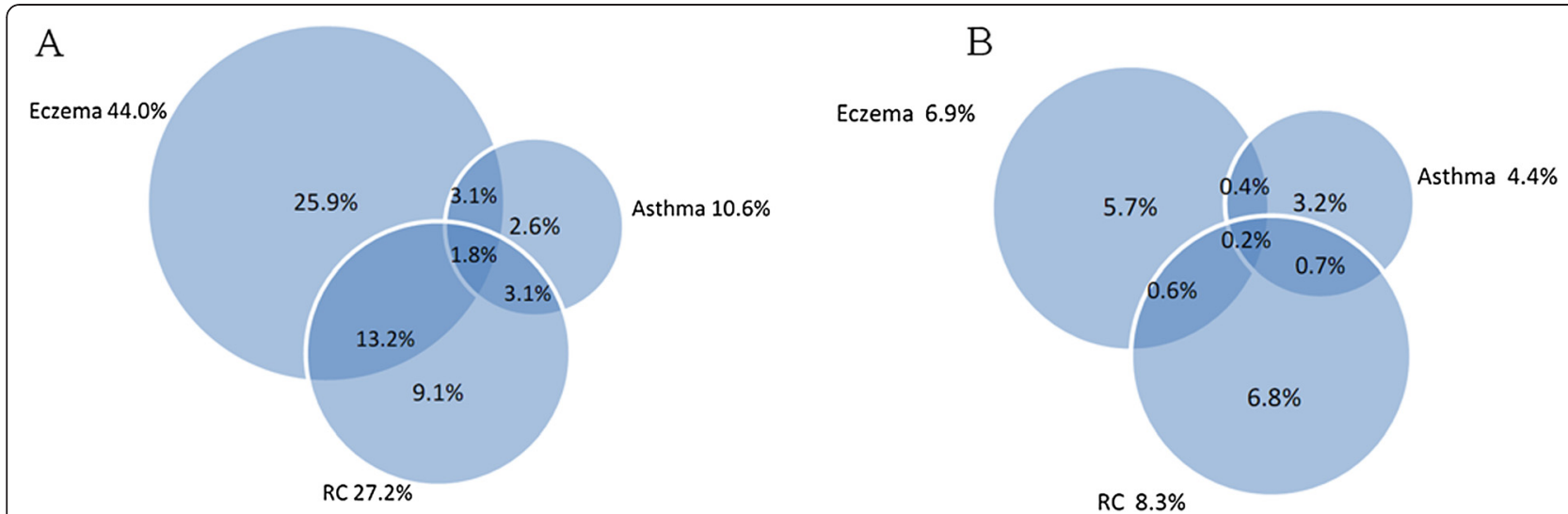

Figure 1 Co-existence of allergy-related diseases reported at age 6 years among children with (A) and without (B) eczema at 2 years of age.

socioeconomic differences, indicated by fewer homeowners and more smoking mothers among children without available data at 6 years, only minor differences were found. This socioeconomic difference between participants and non-participants is a well-known challenge in population-based studies, and has also been reported by others $[7,18]$. The low inclusion rate is most likely due to low inclusion activity among GPs, health visitors and midwives and is not likely a consequence of selfselection among parents and children.

Another possible limitation to the study is the use of questionnaires and parental reporting without a clinical verification for some of the diagnoses. The questionnaires are from the ISAAC study, and for the 2-yearolds, we adapted them to fit with this particular age-group. We have validated the eczema diagnoses among the 2-year-olds against the UKWP diagnostic criteria in another study [14] and the results indicate that the prevalence of eczema in this age-group may be overestimated when self-reported. The reliability of some of the questions regarding health has, however, been tested, and reported doctor-diagnosed asthma and the information obtained from medical records showed excellent agreement [19]. In addition, mother-reported use of anti-asthmatic medications during the previous year among 7-year-old children has been shown to be highly valid [20]. The questions on rhino-conjunctivitis have, to the best of our knowledge, not been validated for 2-yearolds, and due to the high rate of infections with symptoms resembling rhino-conjunctivitis in this age group, the prevalence of rhino-conjunctivitis reported at 2 years must be interpreted with caution.

In addition to the early manifestation of eczema, it is commonly believed that the severity of eczema, male sex, early wheezing, heredity and sensitisation are possible risk factors for the development of childhood asthma. We used information from the clinical investigative subsample, in which $91 \%$ of the children were tested either by SPT or blood sample, regardless of the presence of symptoms, to conduct multiple imputations on missing sensitisation data. In doing so, the sensitisation estimate is less precise. Another limitation regarding sensitisation is the fact that we have only tested the children once, at the age of 2 years. We might therefore have missed the children with transient sensitisation before this age. In addition, there is also a possibility that children are sensitised for allergens not tested for, such as wheat and soybean.

Table 5 Adjusted associations between reported eczema at age 2 years and current asthma at 6 years

\begin{tabular}{|c|c|c|c|c|c|c|}
\hline & \multicolumn{2}{|c|}{ 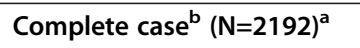 } & \multicolumn{2}{|c|}{ Multiple imputation $^{\mathrm{b}}(\mathrm{N}=4780)$} & \multicolumn{2}{|c|}{ Multiple imputation $^{c}(\mathrm{~N}=4780)$} \\
\hline & OR & $95 \% \mathrm{Cl}$ & OR & $95 \% \mathrm{Cl}$ & OR & $95 \% \mathrm{Cl}$ \\
\hline Eczema & 1.95 & $1.07-3.54$ & 1.92 & $1.21-3.04$ & 1.80 & $1.10-2.96$ \\
\hline Male sex & 1.70 & $0.96-3.00$ & 1.20 & $0.84-1.71$ & 1.19 & $0.83-1.71$ \\
\hline Atopy in family & 2.30 & $1.06-4.96$ & 1.84 & $1.06-3.20$ & 1.74 & $0.99-3.05$ \\
\hline Wheezing & 3.61 & $2.06-6.31$ & 2.71 & $1.70-4.32$ & 2.67 & $1.65-4.32$ \\
\hline Sensitisation (any) & - & & - & - & 2.39 & $0.95-6.02$ \\
\hline
\end{tabular}

${ }^{a}$ Numbers of missing data varies for different variables.

${ }^{\mathrm{b}}$ Adjusted for homeowner, smoking mother, male sex, atopy in family and wheezing.

${ }^{\mathrm{c}}$ Adjusted for ${ }^{\mathrm{b}}$ plus sensitisation. 
Table 6 Adjusted associations between the eczema age of onset at 2 years and current asthma at 6 years

\begin{tabular}{|c|c|c|c|c|c|c|}
\hline & \multicolumn{2}{|c|}{ 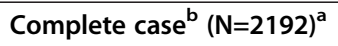 } & \multicolumn{2}{|c|}{ Multiple imputation $^{\mathrm{b}}(\mathrm{N}=4780)$} & \multicolumn{2}{|c|}{ Multiple imputation ${ }^{\mathrm{c}}(\mathrm{N}=4780)$} \\
\hline & OR & $95 \% \mathrm{Cl}$ & OR & $95 \% \mathrm{Cl}$ & OR & $95 \% \mathrm{Cl}$ \\
\hline \multicolumn{7}{|c|}{ Age of eczema onset in tertiles ${ }^{d}$} \\
\hline $0-3$ months & 4.51 & $1.73-11.72$ & 2.18 & $1.03-4.61$ & 1.98 & $0.91-4.28$ \\
\hline 4-12 months & 1.21 & $0.27-5.35$ & 1.40 & $0.61-3.19$ & 1.33 & $0.58-3.04$ \\
\hline$\geq 13$ months & 2.94 & $0.82-10.53$ & 2.11 & $0.72-6.16$ & 2.05 & $0.69-6.07$ \\
\hline Sex & 1.49 & $0.81-2.74$ & 1.29 & $0.83-2.00$ & 1.27 & $0.81-2.01$ \\
\hline Atopy in family & 2.46 & $1.08-5.62$ & 1.81 & $0.99-3.31$ & 1.73 & $0.92-3.23$ \\
\hline Wheezing & 4.98 & $2.72-9.13$ & 2.62 & $1.55-4.43$ & 2.59 & $1.52-4.41$ \\
\hline Sensitisation (any) & - & - & - & - & 2.19 & $0.77-6.20$ \\
\hline
\end{tabular}

${ }^{a}$ Numbers of missing data varies for different variables.

${ }^{\mathrm{b}}$ Adjusted for homeowner, smoking mother, male sex, atopy in family and wheeze.

${ }^{\mathrm{c} A d j u s t e d}$ for ${ }^{\mathrm{b}}$ plus sensitisation.

${ }^{\mathrm{d}}$ Reference group: children with no eczema during the first2 years of life.

The strength of this study is the large number of participants, the unselected population, the prospective design, the random clinical subsample at baseline and the validation of several of the questions.

The prevalence of allergy-related diseases among 6year-olds has been widely documented through the ISAAC study [21]. The 12-month prevalence for eczema in phase III of the study in Sweden, Germany and the UK was $19.5 \%, 7.9 \%$ and $16.0 \%$, respectively. Our finding of $13.6 \%$ is in between the prevalence reported in Germany and the U.K. but, surprisingly, is much lower than in Sweden. The estimated asthma prevalence of $5.5 \%$ is lower than in all three countries $(10.2 \%, 12.8 \%$ and $20.9 \%$, respectively), whereas the prevalence of rhinitis in our study is somewhat higher. The prevalence of eczema, asthma and rhino-conjunctivitis in our cohort of 6-year-olds are, however, well in line with the prevalence found in a Danish birth cohort among children of the same age [22].

Whether eczema is a true risk factor for asthma and rhino-conjunctivitis has been debated, and the relationship between the different allergy-related disorders is unclear. A population-based, longitudinal birth cohort study from the U.K. found that impairment in the skin barrier due to mutations in the FLG gene was associated with an increased risk of eczema, both atopic and nonatopic [13]. In addition, patients with these mutations had more persistent eczema. FLG mutations were also associated with an increased risk of asthma, but only when co-existing with eczema $[9,13]$. Suggestions were made by the authors that the sub-stratification of eczema based on FLG status could identify those children who might benefit from early therapeutic intervention. We did not, however, have the option of FLG testing for the children participating in this study.

We found that only twenty percent of children with eczema at 2 years were sensitised, whereas others have found sensitisation among children in this age group to be approximately one-third [23]. It has been hypothesised that the course of the disease is different for those with sensitisation as opposed to those without sensitisation, and that rather than a progressive atopic march, there are different phenotypes of eczema leading to asthma $[3,24]$. Others have found that FLG mutations with co-existing eczema increase the risk for asthma and hay-fever without an obligate presence of concurrent sensitisation [13]. Our results show an increased risk of asthma at age 6 years among children with eczema at 2 years compared to children without eczema at 2 years, regardless of sensitisation.

\section{Conclusions}

Although most cases of eczema in primary health care are mild to moderate, the findings from this study support the hypothesis of an atopic march in the general population.

\section{Abbreviations}

Cl: Confidence Interval; FLG: Filaggrin; IgE: Immunoglobulin E; ISAAC: International Study of Asthma and Allergies in Childhood; MI: Multiple Imputations; OR: Odds Ratio; PACT: Prevention of Allergy among Children in Trondheim; SCORAD: Scoring Atopic Dermatitis; slgE: Specific Immunoglobulin E; SPT: Skin Prick Test; UKWP: United Kingdom Working Party.

\section{Competing interests}

The authors declare that they have no competing interests.

\section{Authors' contributions}

MS participated in the design of the study, performed the statistical analysis and drafted the manuscript. TØ, OS and RJ conceived of the study,

participated in its design and co-ordination and helped draft the manuscript. PRR performed the statistical analyses and helped draft the manuscript. CKD helped with the statistical analyses and helped draft the manuscript. TLH helped draft the manuscript. All authors read and approved the final manuscript.

\section{Acknowledgements}

The authors would like to thank all parents, children, general practitioners, health visitors and midwives for participating in the study. Special thanks to 
bioengineer Guri Helmersen and nurse Else Bartnes for their invaluable contribution in the PACT-study.

\section{Author details}

'Department of Public Health and General Practice, Norwegian University of Science and Technology, Trondheim, Norway. ${ }^{2}$ Department of Dermatology, St Olav Hospital, Trondheim University Hospital, Trondheim, Norway. ${ }^{3}$ HUNT Research Centre, Department of Public Health and General Practice, Norwegian University of Science and Technology, Trondheim, Norway. ${ }^{4}$ Department of Public Health and General Practice, Medical Research Centre (MTFS), NO-7489, Trondheim, Norway.

Received: 31 January 2012 Accepted: 15 October 2012

Published: 24 October 2012

\section{References}

1. Lowe AJ, Carlin JB, Bennett CM, Hosking CS, Abramson MJ, Hill D t, Dharmage SC: Do boys do the atopic march while girls dawdle? I Allergy Clin Immunol 2008, 121:1190-1195.

2. Almqvist C, Li Q, Britton WJ, Kemp AS, Xuan W, Tovey ER, Marks GB: Early predictors for developing allergic disease and asthma: examining separate steps in the 'allergic march'. Clin Exp Allergy 2007, 37:1296-1302.

3. Illi S, von Mutius E, Lau S, Nickel R, Gruber C, Niggemann B, Wahn U: The natural course of atopic dermatitis from birth to age 7 years and the association with asthma. J Allergy Clin Immunol 2004, 113:925-931.

4. Arshad SH, Kurukulaaratchy RJ, Fenn M, Matthews S: Early life risk factors for current wheeze, asthma, and bronchial hyperresponsiveness at 10 years of age. Chest 2005, 127:502-508.

5. Gustafsson D, Sjoberg O, Foucard T: Development of allergies and asthma in infants and young children with atopic dermatitis-a prospective follow-up to 7 years of age. Allergy 2000, 55:240-245.

6. van der Hulst AE, Klip H, Brand PL: Risk of developing asthma in young children with atopic eczema: a systematic review. J Allergy Clin Immunol 2007, 120:565-569.

7. Martinez FD, Wright AL, Taussig LM, Holberg CJ, Halonen M, Morgan WJ: Asthma and wheezing in the first six years of life. The Group Health Medical Associates. N Engl J Med 1995, 332:133-138.

8. Burgess JA, Lowe AJ, Matheson MC, Varigos G, Abramson MJ, Dharmage SC: Does eczema lead to asthma? J Asthma 2009, 46:429-436.

9. Schuttelaar ML, Kerkhof M, Jonkman MF, Koppelman GH, Brunekreef B, de Jongste JC, Wijga A, McLean WH, Postma DS: Filaggrin mutations in the onset of eczema, sensitization, asthma, hay fever and the interaction with cat exposure. Allergy 2009, 64:1758-1765.

10. Flohr C, England K, Radulovic S, McLean WH, Campbel LE, Barker J, Perkin M, Lack G: Filaggrin loss-of-function mutations are associated with earlyonset eczema, eczema severity and transepidermal water loss at 3 months of age. Br J Dermatol 2010, 163:1333-1336.

11. Palmer CN, Irvine AD, Terron-Kwiatkowski A, Zhao Y, Liao H, Lee SP, Goudie DR, Sandilands A, Campbell LE, Smith FJ, O'Regan GM, Watson RM, Cecil JE, Bale SJ, Compton JG, DiGiovanna JJ, Fleckman P, Lewis-Jones S, Arseculeratne G, Sergeant A, Munro CS, El Houate B, McElreavey K, Halkjaer LB, Bisgaard H, Mukhopadhyay S, McLean WH: Common loss-of-function variants of the epidermal barrier protein filaggrin are a major predisposing factor for atopic dermatitis. Nat Genet 2006, 38:441-446.

12. Marenholz I, Nickel R, Ruschendorf F, Schulz F, Esparza-Gordillo J, Kerscher T, Gruber C, Lau S, Worm M, Keil T, Kurek M, Zaluga E, Wahn U, Lee YA: Filaggrin loss-of-function mutations predispose to phenotypes involved in the atopic march. J Allergy Clin Immunol 2006, 118:866-871.

13. Henderson J, Northstone K, Lee SP, Liao H, Zhao Y, Pembrey M, Mukhopadhyay S, Smith GD, Palmer CN, McLean WH, Irvine AD: The burden of disease associated with filaggrin mutations: a populationbased, longitudinal birth cohort study. J Allergy Clin Immunol 2008, 121:872-877. e879.

14. Smidesang I, Saunes M, Storro O, Oien T, Holmen TL, Johnsen R, Henriksen AH: Atopic dermatitis among 2-year olds; high prevalence, but predominantly mild disease-the PACT study, Norway. Pediatr Dermatol 2008, 25:13-18.

15. Williams H, Flohr C: How epidemiology has challenged 3 prevailing concepts about atopic dermatitis. J Allergy Clin Immunol 2006, 118:209-213.

16. Storro O, Oien T, Dotterud CK, Jenssen JA, Johnsen R: A primary healthcare intervention on pre- and postnatal risk factor behavior to prevent childhood allergy. The Prevention of Allergy among Children in Trondheim (PACT) study. BMC Publ Health 2010, 10:443.

17. Oien T, Storro O, Johnsen R: Intestinal microbiota and its effect on the immune system-a nested case-cohort study on prevention of atopy among small children in Trondheim: the IMPACT study. Contemp Clin Trials 2006, 27:389-395.

18. Illi S, von Mutius E, Lau S, Nickel R, Niggemann B, Sommerfeld C, Wahn U: The pattern of atopic sensitization is associated with the development of asthma in childhood. J Allergy Clin Immunol 2001, 108:709-714.

19. Oien T, Storro O, Johnsen R: Assessing atopic disease in children two to six years old: reliability of a revised questionnaire. Prim Care Respir J 2008, 17:164-168.

20. Furu K, Karlstad O, Skurtveit S, Haberg SE, Nafstad P, London SJ, Nystad W: High validity of mother-reported use of antiasthmatics among children: a comparison with a population-based prescription database. J Clin Epidemiol 2011, 64:878-884.

21. Asher MI, Montefort S, Bjorksten B, Lai CK, Strachan DP, Weiland SK, Williams $\mathrm{H}$ : Worldwide time trends in the prevalence of symptoms of asthma, allergic rhinoconjunctivitis, and eczema in childhood: ISAAC Phases One and Three repeat multicountry cross-sectional surveys. Lancet 2006, 368:733-743.

22. Kjaer HF, Eller E, Host A, Andersen KE, Bindslev-Jensen C: The prevalence of allergic diseases in an unselected group of 6-year-old children. The DARC birth cohort study. Pediatr Allergy Immunol 2008, 19:737-745.

23. Bohme M, Svensson A, Kull I, Nordvall SL, Wahlgren CF: Clinical features of atopic dermatitis at two years of age: a prospective, population-based case-control study. Acta Derm Venereol 2001, 81:193-197.

24. Kusel MM, Holt PG, de Klerk N, Sly PD: Support for 2 variants of eczema. J Allergy Clin Immunol 2005, 116:1067-1072.

doi:10.1186/1471-2431-12-168

Cite this article as: Saunes et al: Early eczema and the risk of childhood asthma: a prospective, population-based study. BMC Pediatrics 2012 12:168.

\section{Submit your next manuscript to BioMed Central and take full advantage of:}

- Convenient online submission

- Thorough peer review

- No space constraints or color figure charges

- Immediate publication on acceptance

- Inclusion in PubMed, CAS, Scopus and Google Scholar

- Research which is freely available for redistribution 